\title{
Media representational practices in the Anthropocene Era
}

\author{
Maxwell T. Boykoff \\ Environmental Change Institute, School of Geography and the Environment, South Parks \\ Road, Oxford, OX1 3QY, UK.
}

\begin{abstract}
Media representational practices are vitally important to conceptions of challenges and possibilities for action to address the issue of anthropogenic climate change. They shape processes between science, policy and the public and thereby influence issues of governance and practices in our everyday lives and livelihoods in the twenty-first century. Many complex factors contribute to media representation practices: external (such as political economic challenges associated with corporate media consolidation) as well as internal influences (such as contributions from the deployment of journalistic norms). In this chapter, I touch on salient and swirling factors that contribute to how issues, events and information have often become climate 'news' about anthropogenic climate change. To the extent that these pressures have led to problematic representational practices, media coverage of climate change has contributed to misperceptions, misleading debates, and divergent understandings. Such practices are therefore detrimental to efforts that seek to enlarge rather than constrict the spectrum of possibility for appropriate responses to various environmental challenges.
\end{abstract}

Keywords: climate change, media, discourse, framing, representations, anthropogenic.

\section{Introduction}

How many reading this chapter start their day with a cup of coffee or tea and the latest peer-reviewed scientific journal article? Rather, how many turn more frequently to a media source, such as television or radio news, a newspaper or the internet for science news? I would suspect the responses favor the latter. Beyond readers here, studies have consistently found that the public garners much of its knowledge about science (and more specifically climate change) from the mass media (e.g., Nelkin, 1987; Wilson, 1995). Frequently and necessarily, global citizens rely on mass media to translate the 'unruly complexities' of climate science into digestible morsels of news and commentary. 
When producing 'news', journalists and editors face an inevitable series of choices regarding how to portray aspects of the climate issue within a larger current of dynamic activities. In other words, they must consider how to 'frame' it. Framing is an inherent facet of cognition, contextualizing and organizing the dynamic swirl of issues, events and occurrences we encounter. Consequently, elements of discourse then privilege certain views and interpretations over others (Goffman, 1974). Over time, various actors - both individuals and collective have sought to access and utilize mass media sources in order to shape perceptions of various aspects of the climate change issue (Nisbet and Mooney, 2007). In this high-stakes and heavily politicized 'battlefield of knowledge', mass media have proven to vitally contribute to shaping dynamic interactions between science, policy and the public. Influencing content, some have asserted that aspects of climate sciences have been overly hyped through the mass media, while others have considered coverage overly laden with inaccurate consternation of the science.

\section{Media and climate risk: an abridged history}

Concurrent with early studies of climate change during the 1700 s and early 1800 s modern media had begun early stages of what was to become its rapid development. During that time, media growth faced constraints by a number of competing and contradictory factors, such as strong state-control over the public sphere, legacies of colonialism, low literacy rates and technological capacity challenges (Starr, 2004). However, in the mid-1800s, media communications expanded their reach and influence tremendously in North America and Europe. Media took shape primarily as mass-circulation print presses in urban centers, where daily newspaper production quadrupled in 40 years, and circulation grew from 0.34 papers per household in 1870 to 1.21 papers per household in 1910 (Starr, 2004). Thus, during this time, mass media outlets formed increasingly significant and powerful social, political, economic and cultural institutions (Starr, 2004).

Climate science and mass media first came together in coverage of climate change in the 1930s. In the New York Times it was written, "The earth must be inevitably changing its aspect and its climate. How the change is slowly taking place and what the result will be has been considered..." (New York Times, 1932, 4). Media coverage of human contributions to climate change appeared more clearly in the 1950s. For instance, the Saturday Evening Post published a story by Abarbanel and McClusky (1950), entitled 'Is the World Getting Warmer?', exploring links between atmospheric temperature change and agricultural shifts as well as sea level rise. In 1956, Kaempffert wrote for the New York Times, "Today more carbon dioxide is being generated by man's technological processes than by volcanoes, geysers and hot springs. Every century man is increasing the carbon dioxide content of the atmosphere by $30 \%$ - that is, at the rate of $1.1^{\circ} \mathrm{C}$ in a century. It may be a chance coincidence that the average temperature of the world since 1900 has risen by about this rate. But the possibility that man had a hand in the rise cannot 
be ignored." (Kaempffert, 1956, 191). Then in 1957 - the International Geophysical Year - science reporter Robert C. Cowen wrote an article that appeared in the Christian Science Monitor called 'Are Men Changing the Earth's Weather?' The article began:

Industrial activity is flooding the air with carbon dioxide gas. This gas acts like the glass in a greenhouse. It is changing the earth's heat balance. It could bring anything form an ice age to a tropical epoch.... Every time you start a car, light a fire, or turn on a furnace you're joining the greatest weather "experiment" men have ever launched. You are adding your bit to the tons of carbon dioxide sent constantly into the air as coal, oil and wood are burned at unprecedented rates (Cowen, 1957).

However, in the subsequent three decades, mass media coverage regarding climate change remained sparse. These pieces regarding human's role in a changing climate served to be a rare instances of media coverage of climate science, as well as clarity regarding anthropogenic climate change. There was scant newspaper, radio and television news coverage on topics such as U.S. National Academy of Sciences reports in the 1960s and 1970s that made repeated reference to emergent climate science, and links to anthropogenic sources.

International and domestic climate policy began to take shape in the mid-1980s, primarily through activities of the International Council of Scientific Unions, the United Nations Environment Program and the World Meteorological Organization. In 1985, the Villach Conference convened in Austria to examine impacts of greenhouse gas emissions on the planet. Meanwhile, modern media communications were taking their present globalized form, marked prominently by increased corporate concentration, conglomeration and commercialism (McChesney, 1999). Media power continued to grow, as did conflicting pressures of corporate control and democratic principles (Graber, 2000; Doyle, 2002). The three media-sciencepolicy spheres collided in the mid-1980s, when media coverage of climate change science and policy increased dramatically. ${ }^{1}$ To illustrate, Figure 1 shows that the quantity of 'climate change' or 'global warming' coverage in forty of the most influential English-language world newspapers has risen over time, like increases in global atmospheric temperature. Increases have been noted during the times of the releases of the Intergovernmental Panel on Climate Change (IPCC) assessment reports in 1990, 1995 and 2001. There are also increases in coverage during the 1992 UN Framework Convention on Climate Change (UN FCCC) and the 1997 Kyoto Protocol. A large increase in coverage was evident in Australia, New Zealand, the Middle East, Asia, Eastern Europe and South Africa during the 1997 Kyoto Protocol. At the meetings in Kyoto, Japan, registrants included 3500 journalists from over 400 media organizations in 160 countries (Leggett, 2001).

\footnotetext{
${ }^{1}$ Various studies in different countries demonstrate an increase in media coverage beginning in 1988: in the United States (Boykoff and Boykoff 2004), Germany (Weingart et al. 2000) and United Kingdom (Carvalho and Burgess 2005).
} 

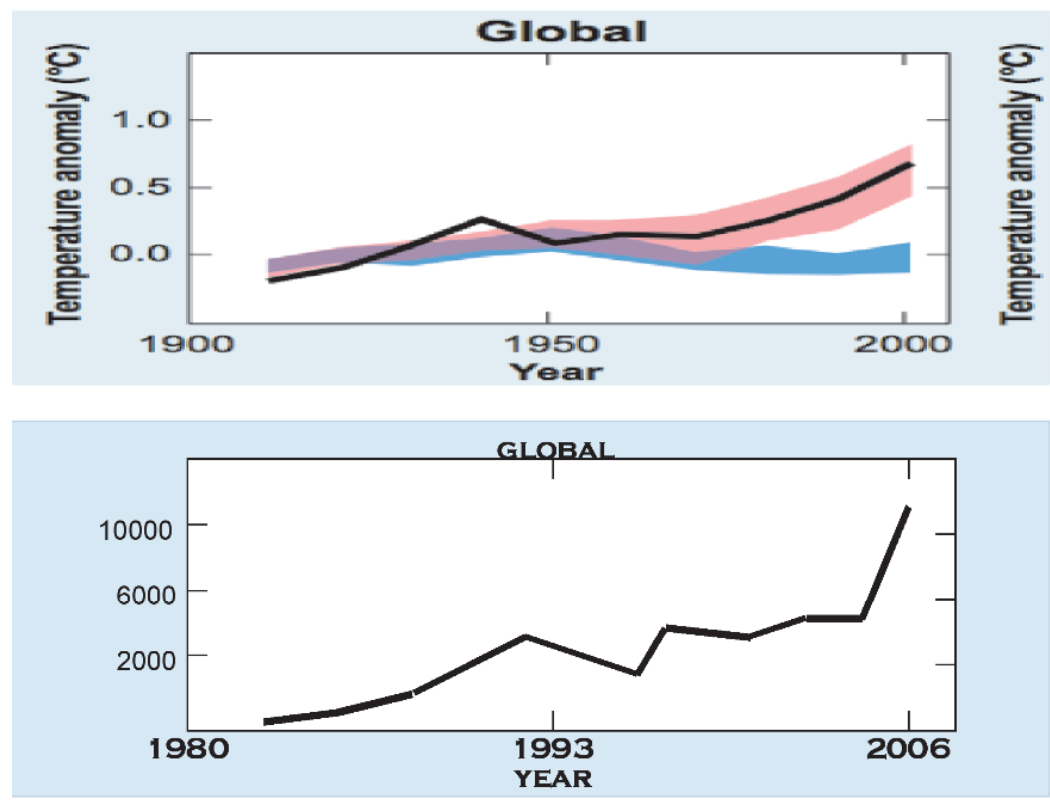

Fig. 1. The plot of global temperature anomaly over time (top) is from the Fourth Assessment Report Working Group I Summary for Policymakers from the Intergovernmental Panel on Climate Change (IPCC, 2007). The black line depicts decadal averages of observations relative to the corresponding temperature average for 1901-1950. The blue hand shows the general range from simulation runs in climate models using only natural forcings due to volcanic and solar activity. The red band shows the range using both natural and anthropogenic forcings. The plot of number of newspaper articles over time (bottom) shows the general trends in the amount of coverage in forty of the most influential English-language newspapers, across seventeen countries and on five continents: the Sydney Morning Herald, The Age (Melbourne), the Courier-Mail (Brisbane), The Australian, the Daily Telegraph (Sydney), Globe and Mail (Toronto), the Toronto Star, the South China Morning Post (Hong Kong), the Prague Post, the Irish Times (Dublin), the Jerusalem Post, the Jerusalem Report, Yomiuri Shimbun (Tokyo), the Japan Times (Tokyo), Mainichi Shimbun (Tokyo), the Korea Herald, the Korea Times (Seoul), the New Straits Times (Wilayah Persekutuan), Het Financieele Dagblad (Eindhoven), the New Zealand Herald (Auckland), the Dominion Post (Wellington), The Press (Christchurch), the Moscow News, the Moscow Times, The Straits Times (Singapore), Business Day (Johannesburg), the Financial Mail (Johannesburg), the Sunday Times (Johannesburg), The Nation (Bangkok), the Guardian (London), the Observer (London), the Independent (and Sunday Independent) (London), the Times (and Sunday Times) (London), the Financial Times (London), The Herald (Glasgow), The Scotsman (and Scotland on Sunday) (Edinburgh), the Los Angeles Times, the New York Times, U.S.A Today (McLean, VA), the Wall Street Journal (New York), and the Washington Post. (This figure is adapted from Boykoff, 2008.)

Many factors contributed to the initial rise in coverage in 1988. Among them was NASA scientist James Hansen's testimony to the U.S. Congress that summer. Hansen testified that he was "99\% certain" that warmer temperatures were caused by the burning of fossil fuels and not solely a result of natural variation (Shabecoff, 
1988, A1). Moreover, this summer was one marked by extreme drought and high temperatures throughout North America. These concomitant events were thought to sensitize many in the climate science and policy communities, as well as the media and public, to the issue of climate change. Demeritt has asserted, "The 1988 heat wave and drought in North America were arguably as influential in fostering public concern as any of the more formal scientific advice" (Demeritt, 2001, 307). In the science and policy spheres, 1988 was also the year in which UNEP and WMO created the IPCC, and the WMO held a landmark international conference called 'Our Changing Atmosphere' (Gupta, 2001). ${ }^{2}$ Overall, Ungar has written, "what rendered 1988 so extraordinary was concatenating physical impacts felt by the person in the street" (Ungar, 1992, 490). These climate change science and policy events and activities were pivotal in shaping media coverage from 1988 forward, during the time when multi-national media corporations underwent further and significant consolidation, through various mergers and acquisitions (Bagdikian, 2004).

Generally, increases in media coverage can be attributed to concatenate ecological/ meteorological, cultural, scientific and political events and issues (Boykoff, 2007a,b). For instance, the powerful 2005 hurricane season, the 2006 drought in Australia and 2007 floods in the UK have fed into many media stories. Culturally-relevant events like the 2006 release of the film 'An Inconvenient Truth', and fluctuating oil and gas prices in 2006 and 2007 have contributed to surges in news reporting in Western Europe and North America. Increases have also been connected to scientific reports such as the 2006 'Stern Review', and the three 2007 UN Intergovernmental Panel on Climate Change Working Group Reports. Moreover, political events such as the UN Twelfth Conference of Parties meeting to the Kyoto Protocol in Kenya and the June 2007 Group of Eight Summit in Germany have generated substantial climate change media coverage. These interrelated issues have provided abundant journalistic 'news hooks' to reporting on interwoven aspects of carbonbased industry and society. So if media coverage does matter, how does it matter?

\section{Factors that shape climate change media coverage}

Interactions unfolding today at the interface of science, policy and media are steeped in histories that include media institutions and asymmetrical power relationships buttressing journalistic practices therein (Bennett, 2002; Starr, 2004). It is clear that science and politics have influenced media coverage of climate change over time. Conversely, journalistic framings have shaped ongoing scientific and political considerations as well as policy decisions and activities. Moreover, much

\footnotetext{
${ }^{2}$ At this conference in Toronto, 300 scientists and policy-makers representing 46 countries convened, and from this meeting, participants called upon countries to reduce carbon dioxide emissions by $20 \%$ or more by 2005 (Gupta 2001).
} 
as storylines are fueled within environmental politics, the mass media play an important role in framing understandings as an interpreter, translator and disseminator of information.

In this dynamic milieu, has the recent deluge of coverage signaled or prompted a flood of new awareness and motivation to address climate change? Is more coverage 'better' in this respect, or has this contributed to public saturation and despair? What actually is 'good' action based on 'good' information via mass media? In combination, answers to these questions are complex, and influencing elements as they relate to mass media are often subtle as well as contradictory. Nonetheless, here I assemble a mosaic of comments to describe four contingent and multi-scale factors that prominently shape how rising media coverage may (or may not) matter to enhancing public understanding and action.

\subsection{Journalistic accuracy}

Beyond the quantity of coverage is the obvious concern of accuracy. Media professionals - such as editors and journalists - operate within an often-competitive political, economic, institutional, social and cultural landscape. Therefore, the negotiated meanings and representations derive through combined structural and agential components of mass media. These processes take place simultaneously at multiple scales (Boykoff, 2007a,b). Large-scale social, political and economic factors (such as decision-making in a capitalist political economy) influence everyday individual journalistic decisions (such as how to focus or frame a story with limited time to press as well as finite number of column inches). These issues intersect with processes such as journalistic norms and values, such as 'objectivity' and 'balance' (Boykoff and Boykoff, 2004, 2007a,b). A number of polls have queried reader comprehension of climate change. For instance, research has found that more accurate information on climate change causes increases people's stated intentions to do something about it (Bord et al., 2000). Further, research examining coverage of uncertainty in climate change found that greater contextualization within climate science stories helps to mitigate against controversy stirred up through uncertainty (Corbett and Durfee, 2004).

\subsection{Issue salience}

Various aspects of the climate change issue can become salient for a host of reasons. As an example linked to lives and livelihoods, displaced people and affected communities due to sea level rise make this a more prominent issue for them. Similarly, farmers facing new dangers of flooding or drought may consider climate change as an important driver, and thus, concern. However, a 2006 study found that beliefs about climate change were a function of three main factors: possible relevant personal experiences (e.g., exposure to weather disasters), perceived consequences 
of climate change (e.g., relative vulnerability) and messages from informants (e.g., scientists via the mass media). Through this empirical research, the authors put forward a mechanism linking knowledge and action: "knowledge may have increased certainty, which in turn increased assessments of national seriousness, which in turn increased policy support...knowledge about an issue per se will not necessarily increase support for a relevant policy. It will do so only if existence beliefs, attitudes, and beliefs about human responsibility are in place to permit the necessary reasoning steps to unfold" (Krosnick et al., 2006, 36, 37). Despite some of our best intentions, the reality often is that our behaviors may not match our concern if the issue does not significantly impact the functioning of our daily lives.

\subsection{Geography}

Related to issue salience, differences between humans and physical landscapes (and the processes that affect them) across space influence perceptions of climate change. Mass media is an important driver in these variegated perceptions (Boykoff, 2007a,b). Recent AC Nielsen polling captures these differences over time (Figure 2).

concern for global war ming 'over next six months'

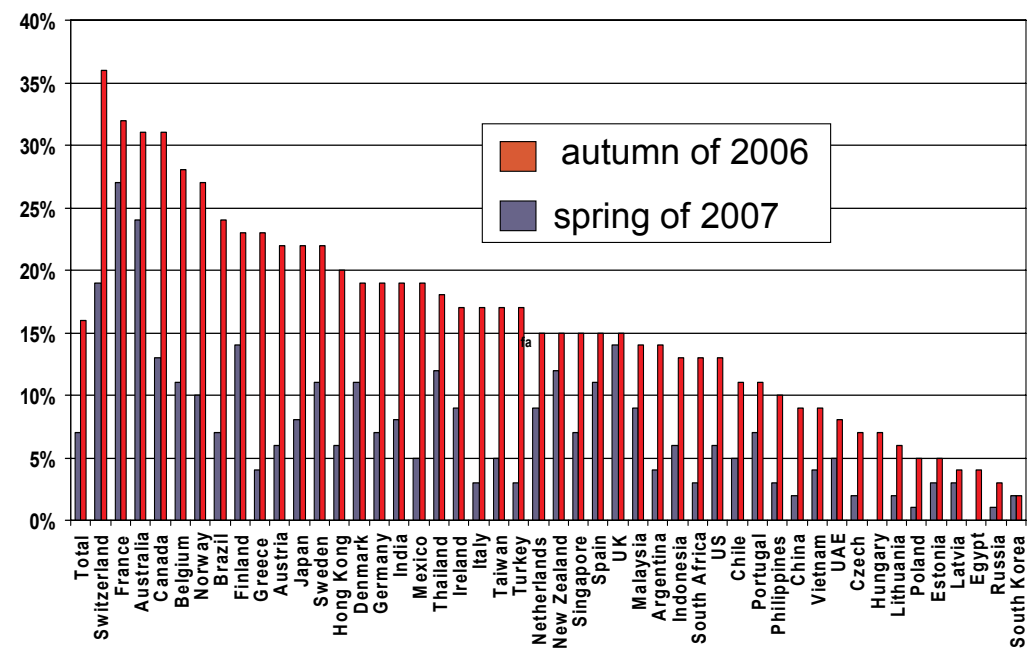

Fig. 2. This figure depicts the changing concern for climate change through an online 47-country survey between autumn 2006 (in red) and spring 2007 (in blue). To the question 'what is your biggest and second biggest concern over the next six months, $16 \%$ of 26,486 respondents in Spring 2007 selected 'global warming', up from 7\% in autumn 2006. Global warming moved past 'terrorism', 'war', 'crime' and 'political stability' into the fourth biggest concern after 'economy', 'health' and 'job security'. This figure was initially assembled by Jonathan Banks, Business Insight Director at AC Nielsen. (AC Nielsen, 2007). 
To the question 'what is your biggest and second biggest concern over the next six months', respondents selected global warming more than two times more frequently in spring 2007 than six months previously (AC Nielsen, 2007). However, within this general trend there are many geographic disparities. For instance, in UK the increase moved from $14 \%$ to $15 \%$ concern, while concern in the US jumped from $6 \%$ to $13 \%$. Meanwhile, since 2003 reporting in daily print media has roughly quadrupled in the UK and tripled in the US (Boykoff and Rajan, 2007). On one hand, this shows that stated concern in the US remains lower than that in the UK. On another hand, this may indicate that despite dramatic increases in media reports, the UK may be saturated on this issue while it contributes to a rise in concern in the US. Clearly, there are many explanatory limits to these connections with online polling and national aggregates. It harkens to the Roberts Chambers classic intervention into 'whose reality counts' (Chambers, 1997). Nonetheless, such juxtapositions provide opportunities to explore these differences in human and physical geography, as situated in varied histories and political contexts.

\subsection{Information and/or education}

Studies have shown that without some kind of knowledge of science to help provide a foundation of understanding to follow ongoing issues, more journalism will not help (Miller, 1997). Moreover, attempts to agree on 'appropriate' action such as in the case of purchasing carbon offsets for air travel - can prove to be highly contested. Ungar $(2000,309)$ has argued that through various mass media processes, "the public could very well be concerned but relatively ill informed". So in this case more media coverage may not be helpful. Journalists and editors have consistently stated that their role as one of information dissemination rather than education. However, in practice, the distinction between these roles becomes blurred. Media representations, by their very nature, frame aspects of climate change, so such practices inevitably contribute to how people understanding them. Turning to climate science education in schools and university, it generally has been slow to permeate curricula amid the growing instrumental approaches to educational practices. Furthermore, relying on the leaders of tomorrow through education to tackle what many consider a pressing contemporary issue may be deemed a form of inter-generational irresponsibility.

\section{Continuing challenges at the climate science-media-policy/practice interface}

When Smith (2000) assembled the valuable edited book The Daily Globe: Environmental change, the public and the media in 2000, the science-media-policy/ practice landscape looked much different. At that time, Smith asserted that such 
issues were 'routinely underreported', and connected this to problems in appropriate actions to address environmental degradation. However, now that climate change is often widely reported through mass media outlets, it remains an open question as to how this really may connect to multi-scale action, from individual to international mitigation and adaptation practices.

Nonetheless, mass media comprise a community where these issues can readily and potentially effectively be addressed, analyzed and discussed. This is a complex arena: mass media portrayals simply do not translate truths or truth-claims nor do they fill knowledge gaps for citizens and policy actors to make 'the right choices'. If only things were that straightforward. In fact, increased media attention to the issue often unearths more questions to be answered and greater scientific understanding actually can contribute to a greater supply of knowledge from which to develop and argue varying interpretations of that science (Sarewitz, 2004). While this can vary depending on which aspect of climate change one is focused on - from anthropogenic signals and noise to what should be done about it - the interacting factors can simultaneously illuminate and obfuscate connections between media coverage and public engagement.

In theorizing interactions at the science-practice interface, researchers have considered three main 'waves' of engagement (Collins and Evans, 2002). The first wave of interactions was that of a 'deficit model' approach to understanding interaction. This perspective posited that poor choices and actions were attributed to 'deficits' of knowledge and information to make the 'correct' choice. The approach was associated with norms and ideals of science as open, universal and objective practices. However, this set of ideal interactions is much more complicated in practice. Since the 1950s, this view has been critiqued (mainly within the discipline of science studies) for being too simple a characterization of the dynamic interactions between science and policy/practice. However, in the policy and public spheres, there are residual impulses such as the stated reliance on 'sound' science in order to make decisions, as well as the stated pursuits to eliminate uncertainty as a precondition for action. The second wave of engagement is considered the wave of 'democracy'. Ulrich Beck examined the democratization of the sciencepractice interface, particularly in his book 'Risk Society' (Beck, 1992). There he posited that there are common 'bads' in our risk society as well as common 'goods': techno-economic development itself could actually increase problems in practice rather than solve them. He called for more non-state actor/policy/public engagement and feedback into the processes of science (or 'upstream engagement') in order to more properly account for and deal with the contested spaces of (public and private) engagement with science. The third wave is called the 'normative theory of expertise'. It is similar to the second wave in terms of the democratizing commitments, though it further maps institutional boundaries between formalized science-policy/politics and the lay public. This theoretical move seeks to delineate the variegated roles of generally legitimized and authorized 'experts' vis-à-vis specialist 'experts' in the field in question. In other words, in the case of 
climate change, this modeling seeks to clarify which groups and institutions may be 'authorized' speakers on climate science, while others are not (Collins and Evans, 2002).

\section{The public space where climate science and practice interact via mass media}

Taken together, 'awareness' and 'knowledge', broadly construed, can prompt a range of responses in the public sphere. With and without access to accurate information on climate change science and policy/practices, people can often feel overwhelmed or paralyzed, and 'switch off' to possibilities for smaller-scale changes that can potentially aggregate to larger changes to address this global issue. For instance, media reporting on the Live Earth July 2007 concerts may inspire and motivate some people to strive for more low-carbon lifestyles. Meanwhile, media attention on the events might irk others, and cause them to surrender their carbon sacrifices as they learn of the high carbon-intensity lifestyles of some of the performers. Borrowing from David Foster Wallace, self-sacrifice in the face of such a diffuse problem could be deemed 'supposedly good things I'll never do again'.

While all humans are implicated to varying degrees in contributing to sources of greenhouse gas emissions - through household activities, engagement in industrial activities through consumption, transport - those experiencing concentrated impacts are much fewer. So while responsibility is diffuse, subsets of more vulnerable human groups feel the concentrated costs. This 'depersonalization' is also reflected in intersecting research on public trust and climate change action. Lorenzoni and Pidgeon $(2006,88)$ have found that, "successful action is only likely to take place if individuals feel they can and should make a difference, and if it is firmly based upon the trust placed in government and institutional capabilities for adequately managing risks and delivering the means to achieve change". On a community level, public perceptions of trust are shaped by varied political contexts and histories often translated via mass media practices. Then on an individual level, conflicts between knowledge and behavior may also stir up anxiety (or cognitive dissonance) between what one knows what one ought to do, and what one actually does. Again, mass media coverage has proven to be a key contributor - among a number of factors - that have shaped and affected science and policy discourse as well as public understanding and action. Amid a number of open questions raised, it can be said with certainty that more media coverage of climate change - and fair and accurate coverage at that - will not 'solve' the problem. Moving forward, it is our perhaps diffuse yet shared responsibility to continue to consider the variegated role of mass media in improving public understanding of climate science and enhancing policy implementation. 


\section{References}

Abarbanel, A. and T. McClusky (1950). Is the world getting warmer? Saturday Evening Post 22, 23, 57: 60-63.

AC Nielsen (2007). Global Omnibus Survey. Oxford, UK, AC Nielsen.

Bagdikian, B. (2004). The Media Monopoly. Boston, Beacon Press.

Beck, U. (1992). Risk Society: Towards a New Modernity. London, Sage.

Bennett, W. L. (2002). News: The Politics of Illusion. New York, Longman.

Bord, R. J., R. E. O'Connor, and A. Fisher (2000). In what sense does the public need to understand global climate change? Public Understanding of Science 9: 205-218.

Boykoff, M. T. (2007a). Flogging a dead norm? Newspaper coverage of anthropogenic climate change in the United States and United Kingdom from 2003-2006. Area 39(4): 470-481.

Boykoff, M. T. (2007b). From convergence to contention: United States mass media representations of anthropogenic climate change science. Transactions of the Institute for British Geography 32(4): 477-489.

Boykoff, M. T. (2008). The real swindle, Nature Reports Climate Change 2(2): 31-32.

Boykoff, M. T. and J. M. Boykoff (2004). Bias as balance: Global warming and the U.S. Prestige Press. Global Environmental Change 14(2): 125-136.

Boykoff, M. T. and J. M. Boykoff (2007). Climate change and journalistic norms: A case study of U.S. mass-media coverage. Geoforum 38(6): 1190-1204.

Boykoff, M. T. and S. R. Rajan (2007). Signals and noise: Mass-media coverage of climate change in the USA and the UK. European Molecular Biology Organization Reports 8(3): $1-5$.

Carvalho, A. and J. Burgess (2005). Cultural circuits of climate change in UK broadsheet newspapers, 1985-2003. Risk Analysis 25(6): 1457-1469.

Chambers, R. (1997). Whose Reality Counts? Putting the First Last. London, ITDG Publishing

Collins, H. M. and R. Evans (2002). The third wave of science studies: Studies of expertise and experience. Social Studies of Science 32(2): 235-296.

Corbett, J. B. and J. L. Durfee (2004). Testing public (un) certainty of science: Media representations of global warming. Science Communication 26(2): 129.

Cowen, R. (1957). Are Men Changing the Earth's Weather? Christian Science Monitor. Boston, Massachusetts, USA 13.

Demeritt, D. (2001). The construction of global warming and the politics of science. Annals of the Association of American Geographers 91(2): 307-337.

Doyle, G. (2002). Media Ownership: The Economics and Politics of Convergence and Concentration in the UK and European Media. London, Sage Publications.

Goffman, E. (1974). Frame Analysis: An Essay on the Organization of Experience. Harvard University Press, Cambridge, Massachusetts, USA.

Graber, D. (2000). Media Power in Politics. Washington D.C., CQ Press.

Gupta, J. (2001). Our Simmering Planet: What to Do About Global Warming? New York, NY, Zed Books.

IPCC (2007). Climate Change 2007: The Physical Science Basis, Summary for Policymakers. Cambridge University Press, Cambridge, UK.

Kaempffert, W. (1956). Science in review: Warmer climate on Earth may be due to more carbon dioxide in the air. New York Times. New York: 191.

Krosnick, J. A., A. L. Holbrook, L. Lowe, and P. S. Visser (2006). The origins and consequences of democratic citizens' policy agendas: A study of popular concern about global warming. Climatic Change 77(1): 7-43. 
Leggett, J. K. (2001). The carbon war: Global warming and the end of the oil era. New York, Routledge.

Lorenzoni, I. and N. F. Pidgeon (2006). Public views on climate change: European and USA perspectives. Climatic Change 77(1): 73-95.

McChesney, R. W. (1999). Rich Media, Poor Democracy: Communication Politics in Dubious Times. Urbana and Chicago, University of Illinois Press.

Miller, B. (1997). Political action and the geography of defense investment: Geographical scale and the representation of the Massachusetts Miracle. Political Geography 16: $171-185$.

Nelkin, D. (1987). Selling Science: How the Press Covers Science and Technology. New York, W.H. Freeman.

New York Times (1932). Next great deluge forecast by science. New York Times. New York: 4.

Nisbet, M. C. and C. Mooney (2007). Framing science. Science 316(6 April): 56.

Sarewitz, D. (2004). How science makes environmental controversies worse. Environmental Science and Policy 7: 385-403.

Shabecoff, P. (1988). Global warming has begun, expert tells senate. New York Times. New York: A1.

Smith, J., Ed. (2000). The Daily Globe: Environmental Change, the Public and the Media. London, Earthscan Publications Ltd.

Starr, P. (2004). The Creation of the Media: Political Origins of Modern Communications. New York, NY, Basic Books.

Ungar, S. (2000). Knowledge, ignorance and the popular culture: Climate change versus the ozone hole. Public Understanding of Science 9: 297-312.

Ungar, S. (1992). The rise and (relative) decline of global warming as a social problem. The Sociological Quarterly 33(4): 483-501.

Weingart, P., A. Engels, et al. (2000). Risks of communication: Discourses on climate change in science, politics, and the mass media. Public Understanding of Science 9: 261-283.

Wilson, K. M. (1995). Mass media as sources of global warming knowledge. Mass Communications Review 22(1\&2): 75-89. 